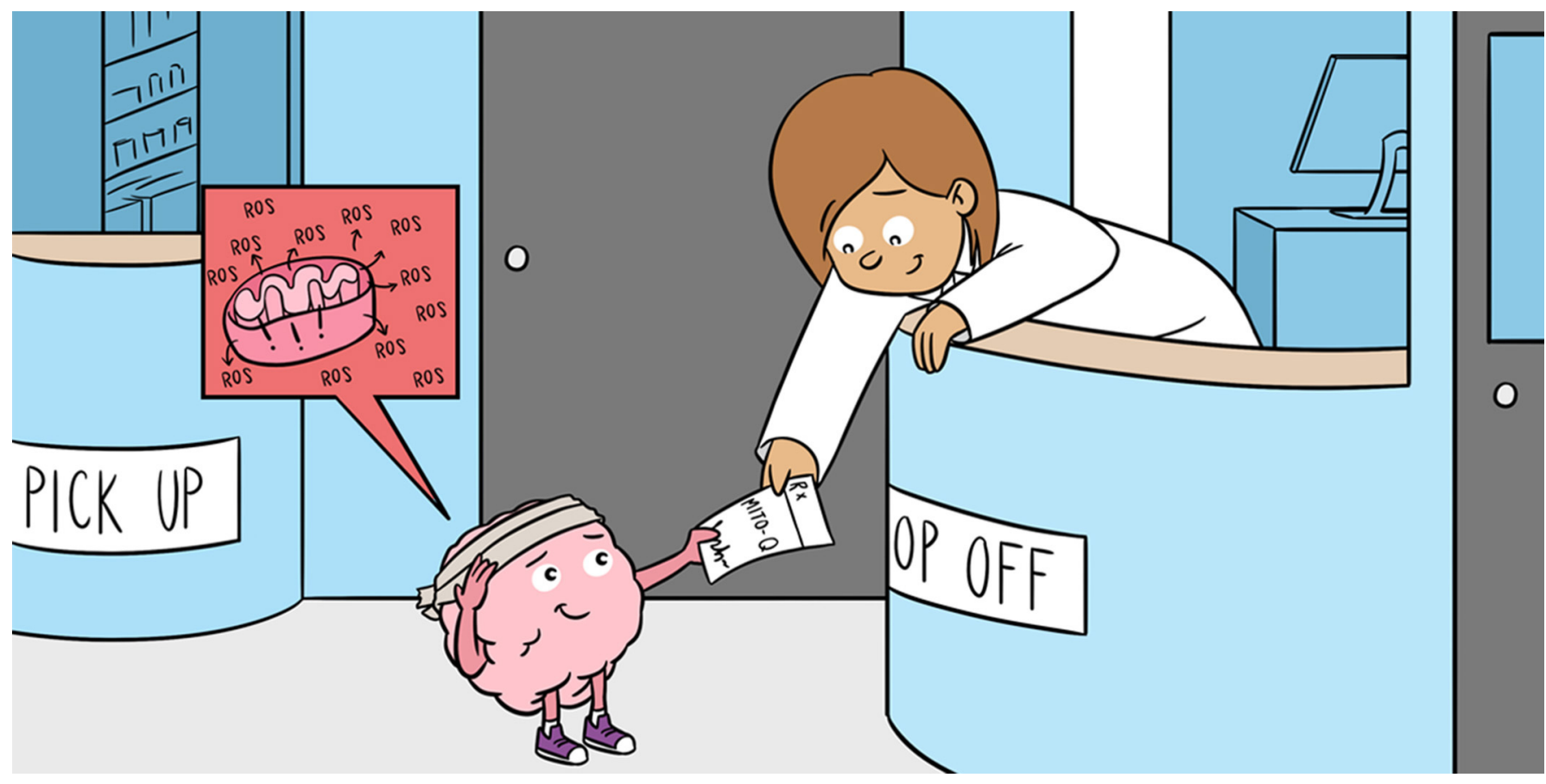

\title{
MITOCHONDRIA IN BRAIN INJURY: ANTIOXIDANTS TO THE RESCUE!
}

Maha Tabet ${ }^{1+}$, Samar Abdelhady ${ }^{1,2+}$, Nour Shaito ${ }^{1}$, Marya El-Kurdi ${ }^{1}$, Hiba Hasan ${ }^{1,3}$, Reem Abedi ${ }^{1}$, Nawara Osman ${ }^{1}$, Riyad El-Khoury ${ }^{4}$, Abdullah Shaito ${ }^{5 *}$ and Firas Kobeissy ${ }^{1^{*}}$

${ }^{1}$ Department of Biochemistry and Molecular Genetics, Faculty of Medicine, American University of Beirut, Beirut, Lebanon

${ }^{2}$ Faculty of Medicine, Alexandria University, Alexandria, Egypt

${ }^{3}$ Department of Anatomy and Cell Biology, Justus Liebig University of Giessen, Giessen, Germany

${ }^{4}$ Neuromuscular Diagnostic Laboratory, Department of Pathology and Laboratory Medicine, American University of Beirut Medical Center, Beirut, Lebanon

${ }^{5}$ Department of Biological and Chemical Sciences, Lebanese International University, Beirut, Lebanon

YOUNG REVIEWERS:

IAGO

AGE: 13

NOVA

AGE: 8
If you have ever bumped your head, then you may have experienced a traumatic brain injury (TBI). TBI is brain damage caused by an outside force. In the long run, TBI may weaken a person's ability to think, learn, or remember. In this article, we will learn how the mitochondria, tiny structures inside our cells, are partly responsible for the harmful effects of TBI. Mitochondria produce most of the energy our cells need to function properly. This, however, comes with a cost. Energy production is accompanied by the release of harmful substances, such as reactive oxygen species (ROS). ROS can damage components inside our cells and even lead to cell death. In TBI, damaged mitochondria produce high amounts of ROS. Drugs called antioxidants may protect the brain following TBI. Antioxidants 
TRAUMATIC BRAIN INJURY

Damage caused to the brain by a bump to the head.

\section{NEURON}

The main type of cells in the brain. They serve to communicate messages within the brain and between the brain and other body organs.

\section{MITOCHONDRIA}

Structures found in our cells responsible for producing the energy our cells need.

\section{REACTIVE OXYGEN} SPECIES

Substances produced by our cells. ROS, in very high levels, can interact with and damage components inside the cell.

\section{ANTIOXIDANT}

Molecules that can be man-made or found in nature, such as in fruits They can protect the cell against the harmful effects of ROS.

\section{can destroy ROS. However, you should never use these drugs without medical guidance.}

\section{WHAT IS TRAUMATIC BRAIN INJURY?}

Have you ever bumped your head? You most likely have. Your brain is vulnerable to impacts that can occur while you are practicing sports, if you have a bad fall, or if you are in a car accident. These impacts can result in a damage to the brain, which is called traumatic brain injury (TBI). TBIs can have varying levels of severity. Severe TBI causes the most damage to the brain. Mild TBI is the most common form of TBI and typically does not cause permanent symptoms. However, if you receive repeated mild TBIs, symptoms may persist. TBI may affect several brain functions, including a person's ability to think, concentrate, learn, and remember things. In the long run, repeated mild TBI may also increase the risk of some diseases caused by the death of main cells of the brain called neurons. Tiny structures inside our cells called mitochondria are partly responsible for these harmful long-term effects of TBI [1].

\section{WHAT ARE MITOCHONDRIA?}

Mitochondria are special structures found inside all of body cells. The main function of mitochondria is the production of the energy our cells need to function. A mitochondrion is made of an outer membrane surrounding a space that contains an inner membrane. The inner membrane surrounds an inner cavity, called the matrix. The inner membrane contains the elements responsible for energy production.

Think of the mitochondria as the power generators of our cells. Similar to real generators that release pollutants as they generate power, mitochondria also produce harmful substances as by-products. Among those harmful by-products are reactive oxygen species (ROS). ROS can interact with and damage components of our cells. The cell has several systems to protect itself from excessive ROS. One protective system consists of substances called antioxidants. Antioxidants can control or remove extra amounts of ROS. Under stressful conditions, such as in TBI, damaged mitochondria generate huge amounts of ROS. The protective antioxidant systems become overwhelmed and fail to destroy the excessive ROS. As a result, many cell components may get damaged, which may lead to death of the cell [2] (Figure 1). 
Figure 1

What are

mitochondria?

Mitochondria are

organelles found in

almost all of our cells,

including neurons. A

mitochondrion is made

up of an outer

membrane, an

intermembrane space,

an inner membrane,

and a space in the

middle called the

matrix. Mitochondria

are responsible for

producing the energy

our cells need.

\section{NEUROTRANSMITTER}

A molecule used for communication between neurons.

\section{INFLAMMATION}

It is a protective biological response that starts under harmful conditions, such as stress. It is one way your body fights infection, injury, or disease. It involves immune cells, blood vessels, and many molecules inside the cell.

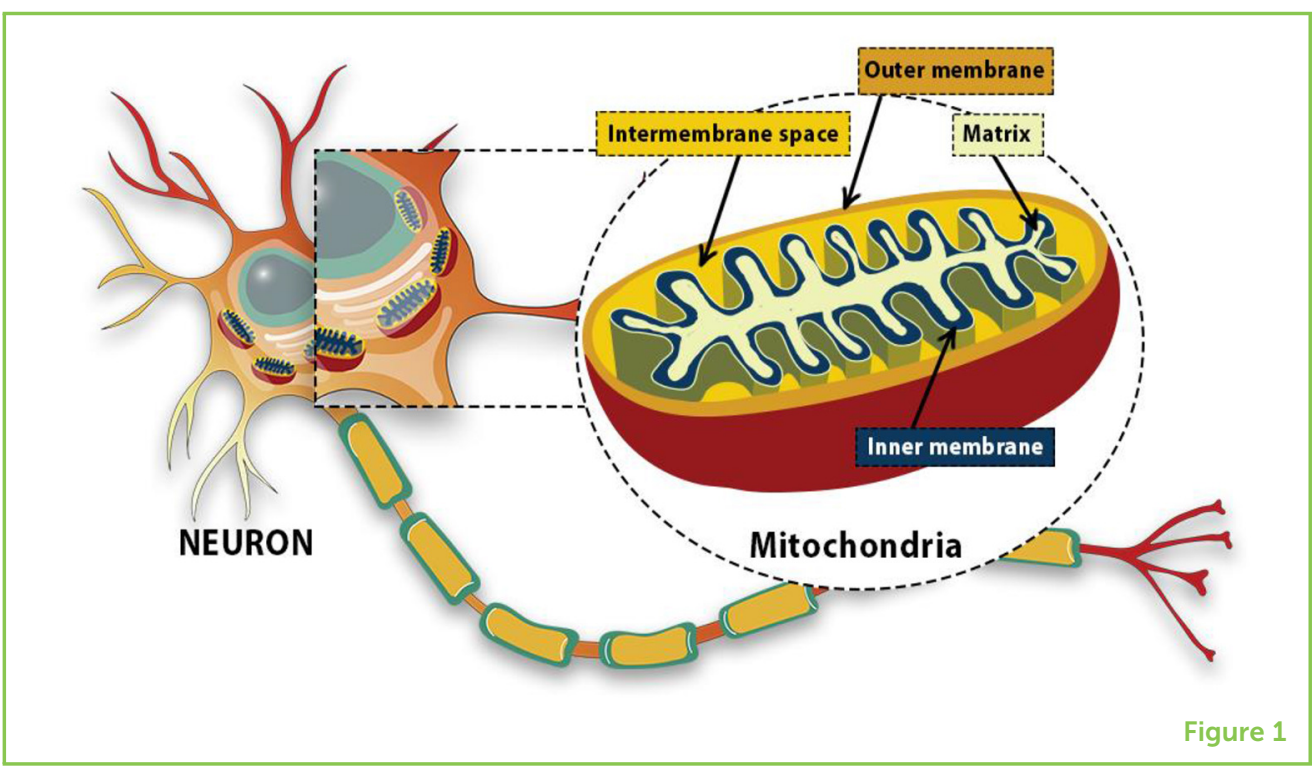

\section{WHAT DO MITOCHONDRIA DO DURING TRAUMATIC BRAIN INJURY?}

The bump on the head is the mechanical force that leads to TBI. Think of it as the force that sets off the falling of a row of domino tiles. After the bump on the head, a series of events takes place in the brain. In the case of a TBI, the mechanical force first causes damage and injury to neurons and may, later, cause their death. The mechanical force also leads to the abnormal release of molecules, called neurotransmitters, used for communication between brain cells. When released, neurotransmitters knock down another domino tile: they cause the abnormal increase of certain substances inside neurons which, in turn, cause the mitochondria to increase production of ROS. ROS then interact with and damage several components inside neurons. Damage to cellular components leads to the impairment of cellular functions. One result of this damage is inflammation in the brain. Damaged cells are set to die [3]. Death of brain neurons is the main problem in TBI (Figure 2).

\section{ANTIOXIDANTS: TO THE RESCUE!}

ROS are one of the main culprits causing neuron dysfunction and death during TBI. If scientists can reduce the levels of ROS in the brain, they may be able to reduce the symptoms of TBI. Antioxidants can act like a sponge that absorbs the harmful amounts of ROS and make them inactive. This ability of antioxidants to reduce the harmful amounts of ROS, in the brain, prevents ROS from damaging the neurons.

So where do we find these antioxidants? Some antioxidants are naturally found in our cells. However, following TBI, antioxidants availability may decrease and our natural antioxidants become 


\section{Figure 2}

Mitochondria in TBI. In undamaged mitochondria, antioxidants help keep the mitochondria healthy and the cell's energy levels normal. However, in TBI, ROS are produced in large quantities and antioxidants get overwhelmed. The mitochondria get damaged and energy production decreases.

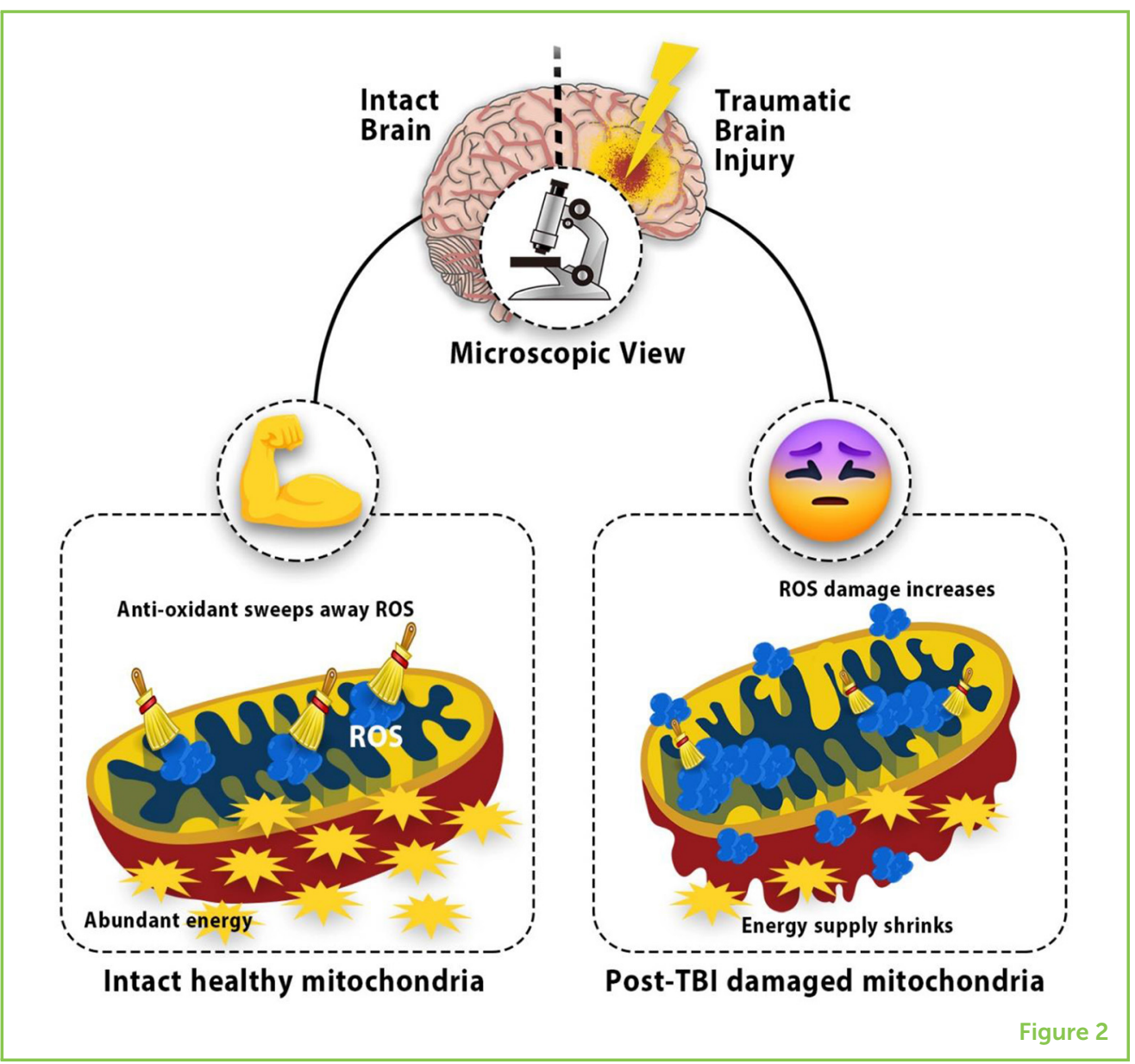

overwhelmed. Extra antioxidants can be provided from outside our body (external antioxidants) in the form of a drug or a supplement. In fact, several of these external antioxidants have been used in the treatment of TBI. Scientists have even found ways to guide the antioxidants to the mitochondria. This is important since mitochondria are the major source of ROS. For example, in our lab, we have used a powerful antioxidant called MitoQ for treating TBI. MitoQ is attached to special guide molecules that can take the antioxidant directly to the mitochondria where ROS are made. This increases the efficiency of the MitoQ drug [3, 4].

\section{CAN HEROES BECOME VILLAINS?}

Another way to look at antioxidants is to imagine antioxidants as heroes that chase the culprits (ROS) and put them in jail in order to save the cell.

Just like almost everything in life, balance is needed when it comes to taking antioxidants. Consuming too many antioxidants can be dangerous. If taken at high dosages, especially when ROS levels are normal, antioxidants may become toxic to cells. Excessive 
Figure 3

Can heroes become villains? Despite the fact that they can protect neurons from harmful ROS, it has been shown that excessive consumption of antioxidants may cause serious diseases, such as cancer. So, we should never take any antioxidant without a doctor's permission.

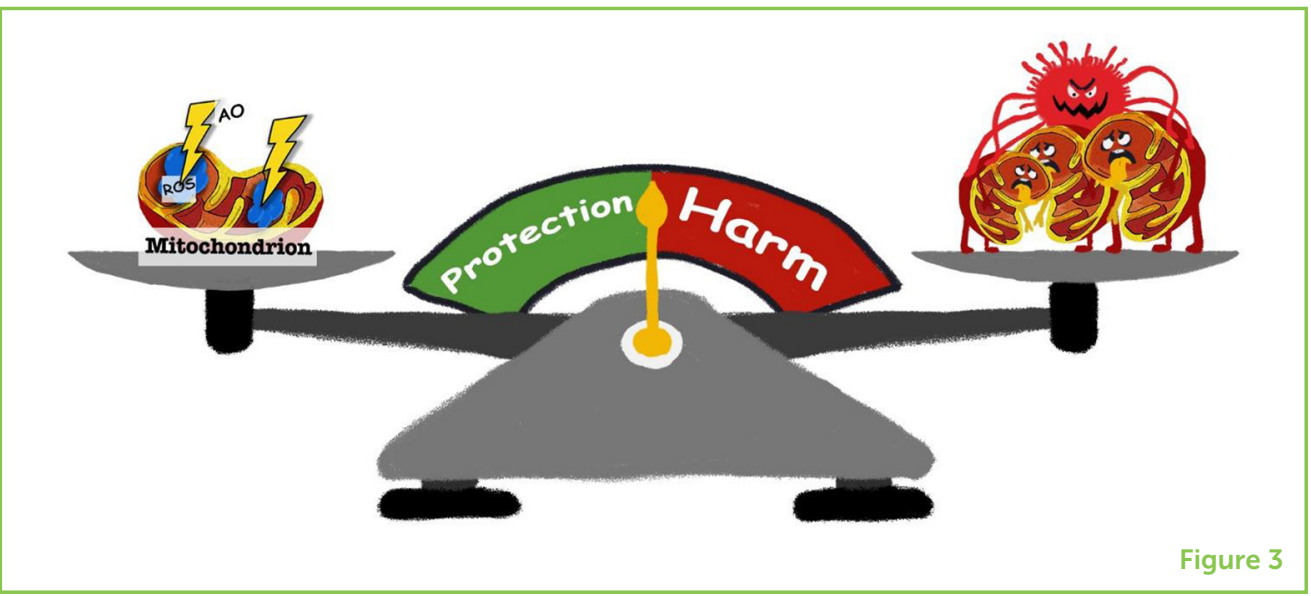

consumption of antioxidants may increase the production of ROS instead of reducing it. Excessive antioxidants may also increase the occurrence of some diseases, including cancer. Therefore, antioxidants should be taken cautiously and under appropriate guidance from a doctor. We do not want our heroes to turn into villains $[5,6]$ (Figure 3)!

\section{CONCLUSION}

Traumatic brain injuries are very common. Finding a treatment is essential to limit their negative consequences. Mitochondria are the structures responsible for energy production inside our cells. In TBI, mitochondria become damaged and produce dangerous amounts of ROS. This can lead to the damage and even the death of the neurons in the brain. Antioxidants may represent a solution to reduce excessive amounts of ROS and reduce the harm of TBI. Scientists have developed ways to target certain antioxidants to the mitochondria to increase the effectiveness of these drugs. Although antioxidants are available without a prescription, it is always important to seek medical advice before consuming these powerful drugs.

\section{REFERENCES}

1. Available online at: https://www.cdc.gov/traumaticbraininjury/index.html (accessed July 28, 2020).

2. Cooper, G. M. 2000. Mitochondria. The Cell: A Molecular Approach. 2 nd Edn. Sunderland, MA: Sinauer Associates.

3. Cheng, G., Kong, R., Zhang, L., and Zhang, J. 2012. Mitochondria in traumatic brain injury and mitochondrial-targeted multipotential therapeutic strategies. Br. J. Pharmacol. 167:699-719. doi: 10.1111/j.1476-5381.2012.02025.x

4. Oyewole, A. O., and Birch-Machin, M. A. 2015. Mitochondria-targeted antioxidants. FASEB J. 29:4766-71. doi: 10.1096/fj.15-275404

5. Mendelsohn, A. R., and Larrick, J. W. 2014. Paradoxical effects of antioxidants on cancer. Rejuv. Res. 17:306-11. doi: 10.1089/rej.2014.1577 
6. Rahal, A., Kumar, A., Singh, V., Yadav, B., Tiwari, R., Chakraborty, S., et al. 2014. Oxidative stress, prooxidants, and antioxidants: the interplay. Biomed. Res. Int. 2014:761264. doi: 10.1155/2014/761264

SUBMITTED: 07 November 2019; ACCEPTED: 17 August 2020;

PUBLISHED ONLINE: 30 September 2020.

EDITED BY: Robert T. Knight, University of California, Berkeley, United States

CITATION: Tabet M, Abdelhady S, Shaito N, El-Kurdi M, Hasan H, Abedi R, Osman N, El-Khoury R, Shaito A and Kobeissy F (2020) Mitochondria in Brain Injury: Antioxidants to the Rescue! Front. Young Minds 8:510817. doi: 10.3389/frym.2020. 510817

CONFLICT OF INTEREST: The authors declare that the research was conducted in the absence of any commercial or financial relationships that could be construed as a potential conflict of interest.

COPYRIGHT @ 2020 Tabet, Abdelhady, Shaito, El-Kurdi, Hasan, Abedi, Osman, El-Khoury, Shaito and Kobeissy. This is an open-access article distributed under the terms of the Creative Commons Attribution License (CC BY). The use, distribution or reproduction in other forums is permitted, provided the original author(s) and the copyright owner(s) are credited and that the original publication in this journal is cited, in accordance with accepted academic practice. No use, distribution or reproduction is permitted which does not comply with these terms.

\section{YOUNG REVIEWERS}

\section{IAGO, AGE: 13}

My name is lago and I am in seventh grade. My favorite subjects are writing, math, social studies, and science. My hobbies are acting, D\&D, and fake-sword fighting. I think it is important for scientists to write for children, so that kids can learn how to think critically and ask questions about how the world works. My mom and dad are "mad" scientists because they stuck a playing card in a brain for a magic trick-good thing the brain was made of Jell-O!

\section{NOVA, AGE: 8}

My name is Nova and I am in third grade. My favorite subjects are writing, science, social studies, and reading. When I grow up, I would like to be an architect, because I like art and I also like building. I think it is important for kids to be curious so they can learn. Albert Einstein said that he did not have a special brain, but he wondered how the universe worked, so he went out and learned, so he could figure it out. 

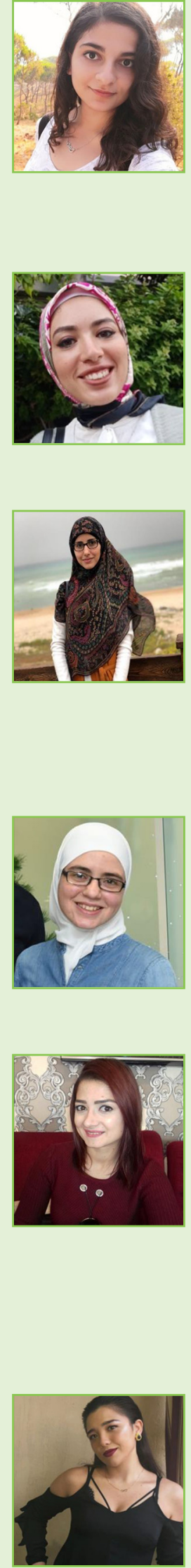

\section{AUTHORS}

\section{MAHA TABET}

I acquired an M.Sc. in Neuroscience from the Neuroscience Research Centre at the Lebanese University and conducted my Master's research project in the department of Biochemistry and Molecular Genetics at the American University of Beirut (AUB). My project examined the role of mitochondria and oxidative stress in traumatic brain injury (TBI), with a focus on testing a possible antioxidant treatment. In addition to my love for research, I like reading, drawing, and writing.

\section{SAMAR ABDELHADY}

I am a medical doctor. I did a research internship in Dr. Kobeissy's lab at the American University of Beirut (AUB) to study traumatic brain injury (TBI) using animal models. In my free time, I love drawing scientific illustrations and brain art, watching movies that talk about the brain, and since I work for long hours at a desk, I enjoy going hiking to keep my body fit.

\section{NOUR SHAITO}

I am currently a Masters Student majoring in Genomics and Health at the Lebanese University. My current research is about the effects of repetitive traumatic brain injury at the behavioral and proteomic levels. Later, I will join Dr. Firas Kobeissy's Lab at the American University of Beirut, with a focus on treating traumatic brain injury using stems cells in combination with drugs. I aim to acquire more experience in the field of neuroscience and to find neuroprotective therapies for neurodegenerative diseases.

\section{MARYA EL-KURDI}

I obtained my B.Sc. degree in Medical Laboratory Sciences at the American University of Beirut (AUB). I got 2 years of work experience in that field before perusing my Master's degree in Biochemistry and Molecular Genetics at AUB. My thesis project, which was done in a neuroscience lab on an animal model of traumatic brain injury, involved both molecular and behavioral studies.

\section{HIBA HASAN}

I am currently a PhD candidate in University of Giessen. Previously, I was a volunteer in the Biochemistry and Molecular Genetics department at the American University of Beirut. The lab focuses on understanding the pathological basis of brain injuries and tests cell- and drug-based therapies for traumatic brain injuries. I have a Master's in Biology with a specialization in Immunology, where I tested the anti-inflammatory and antioxidant activities of different natural agents on autoimmune diseases. I hope to pursue a Ph.D. focusing on the immunopathological basis of autoimmune disorders and hope to find a cure for such diseases.

\section{REEM ABEDI}

I am pursuing my M.Sc. in Neuroscience at the Neuroscience Research Center at the Lebanese University. I am planning to conduct my Master's research project in the department of Biochemistry and Molecular Genetics at the American University of Beirut (AUB), under the supervision of Dr. Firas Kobiessy. My project will 

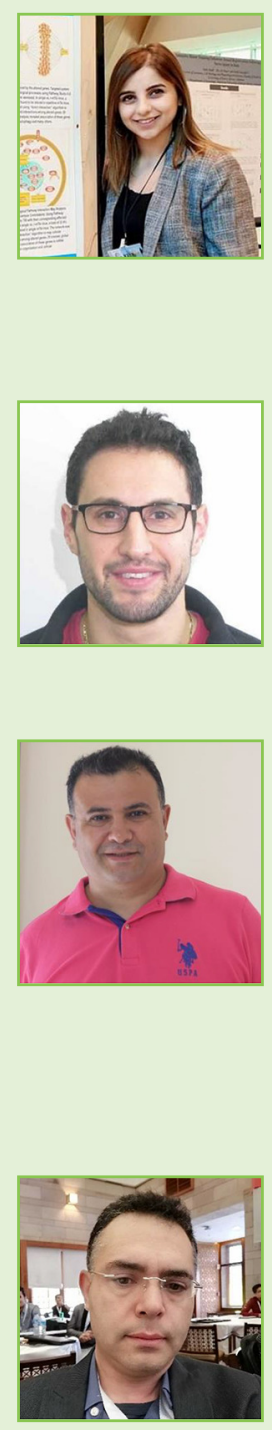

examine the relationship between mitochondria and oxidative stress in traumatic brain injury.

\section{NAWARA OSMAN}

I am a Lebanese research student pursuing a M.Sc. in Biochemistry at the American University of Beirut (AUB), and currently doing my thesis project in Dr. Kobeissy's lab, where I am focusing on the behavioral, molecular, and neuroproteomics aspects of repeated concussions. I earned a Bachelor's degree in Biochemistry from the Lebanese International University. I aim to pursue a doctoral degree and be a part of further achievements in science.

\section{RIYAD EL-KHOURY}

I currently work at the Department of Pathology and Laboratory Medicine, American University of Beirut. My research interests focus on the link between these diseases and mitochondrial dysfunction. Indeed, disturbances in mitochondrial activities are now known to play a major role in many diseases, particularly those affecting the neuromuscular and neurological systems.

\section{ABDULLAH SHAITO}

I obtained my Ph.D. at the University of Texas Southwestern at Dallas (Texas, USA), where I studied microbiota interaction with intestinal cells. Currently, I am an Assistant Professor at the Lebanese International University (Beirut, Lebanon). The current research projects I am working on include the use of stem cells to treat $\mathrm{TBI}$, and the cell-cell communication that happens in different cancers. I also teach several core Biology courses to undergraduates. Email me when you get into college and need help in your Biology courses. *abdshaito@gmail.com

\section{FIRAS KOBEISSY}

I am a neuroscientist with extensive experience in experimental brain injury. I am an assistant Professor at the Department Biochemistry at the American University of Beirut. I obtained my Ph.D. from the University of Florida in the area of neuroscience. My current research focuses on identifying biomarkers for drug abuse toxicity and traumatic brain injury neuroproteomics. I am a member of the Center of Neuroproteomics and Biomarker Research and the Center for Traumatic Brain Injury Studies at the McKnight Brain Institute at the University of Florida. *firasko@gmail.com

${ }^{\dagger}$ These authors have contributed equally to this work 